\title{
Ischemia-modified Albumin to Evaluate Short-term Prognostic of Patients with Acute Coronary Syndrome
}

\author{
Huaming $\mathrm{Mou}^{1}$, Jiang Shao ${ }^{1}$, Jianming Zhang ${ }^{1}$, Jianjun Yang ${ }^{1}$, Shimei $\mathrm{Yu}^{2}$ and Hailong Wang ${ }^{1}$ \\ ${ }^{1}$ Department of Cardiology, Heart Center, Chongqing University Three Gorges Hospital, Chongqing, China \\ ${ }^{2}$ Department of Otorhinolaryngology, Wanzhou First People Hospital, Wanzhou, Chongqing, China
}

\begin{abstract}
In patients with acute coronary syndrome (ACS), the predicted short-term result of ischemic modified albumin (IMA) is still not recognised now. The above have been searched in PubMed, Embase, Medline, Cochrane Library databases, and Wanfang databases from the beginning to June 2020. The study explored that patients with positive of IMA had differences in short-term results compared to negative of IMA. Odds ratios for each study was compiled and conducted for heterogeneity assessment, quality review, publication bias. A total of 684 patients (405 positive patients; 279 negative patients) were included in four studies. Comprehensive analysis found that compared with the negative of IMA in patients with ACS, the positive of IMA in patients with ACS had a high incidence of major cardiovascular adverse events (MACE) (HR 1.85; $p=0.03)$, but there was no significant difference in the occurrence of cardiac death (HR 4.40; $p=0.16$ ). It was concluded that the positive of IMA in patients with ACS is associated with an increased incidence of MACE, but there was no statistically significant difference in incidence of cardiac death. Due to the limited data coming from different research groups in different countries, the diagnostic criteria for the IMA cut-off may be different. Future large randomised controlled trials will be certainly needed to confirm these findings.
\end{abstract}

Key Words: Acute coronary syndrome, Ischemia-modified albumin, Meta-analysis, MACE, Cardiac death.

How to cite this article: Mou H, Shao J, Zhang J, Yang J, Yu S, Wang H. Ischemia-modified Albumin to Evaluate Short-term Prognostic of Patients with Acute Coronary Syndrome. J Coll Physicians Surg Pak 2021; 31(07):841-845.

\section{INTRODUCTION}

The value of ischemic modified albumin (IMA) in short-term prognosis of patients with acute coronary syndrome(ACS), remains unclear, and there are still many controversies in application of IMA in patients with acute coronary syndrome. ${ }^{1}$ It is important to develop diagnosis and treatment plans for patients with ACS, based on risk stratification. ${ }^{2}$ So far, there are two main types of risk stratification methods: the Global Registry of Acute Coronary Events (GRACE) ${ }^{3}$ and the Thrombolysis In Myocardial Infarction (TIMI). The two scoring methods are mainly based on elevated biomarkers as risk factors. ${ }^{4}$ IMA and heart-type fatty acid binding (HFAB) are biomarkers of myocardial ischemia that have been neglected by everyone. ${ }^{5}$

In ACS patients, when myocardium is acutely ischemia, IMA production increases, and as oxidative stress increases, IMA levels are still significantly elevated. The IMA had been proven to be helpful for the diagnosis of ACS. ${ }^{6,7}$

Correspondence to: Dr. Hailong Wang, Department of Cardiology, Heart Center, Chongqing University Three Gorges Hospital, Chongqing, China

E-mail: wangjinlong2007666@163.com

Received: October 13, 2020; Revised: May 07, 2021;

Accepted: May 07, 2021

DOI: https://doi.org/10.29271/jcpsp.2021.07.841
However, in patients with ACS, the prognostic value of IMA has not been systematically evaluated. Studies have shown that IMA has the potential to improve risk prediction once included in riskscores. $^{4,8}$

The aim of this meta-analysis was to investigate the association between IMA and short-term prognosis in patients with ACS.

\section{METHODOLOGY}

This systematic review used the Preferred Reporting Items for Systematic Reviews and Meta-analyses (PRISMA) guidelines. ${ }^{9}$ PubMed, Embase, Medline, Cochrane Library databases, and Wanfang databases were searched from the beginning to June 2020, without limiting the language. The full text of the search included ST-segment elevation myocardial infarction or STEMI, non-ST-segment elevation myocardial infarction or NSTEMI, myocardial infarction or MI, acute myocardial infarction or AMI, acute coronary syndrome or ACS, unstable angina, and ischemic-modified albumin or IMA.

Only controlled trials were screened to assess differences in prognosis between IMA-positive and IMA-negative groups in patients with ACS. The study included only controlled trials with ACS patients, with short-term follow-up data on IMA levels (measured during hospitalisation or one month). Non-controlled trials, researchs of stable angina, researchs where complete information was not available, and researchs that lacked followupresult, were excluded. 


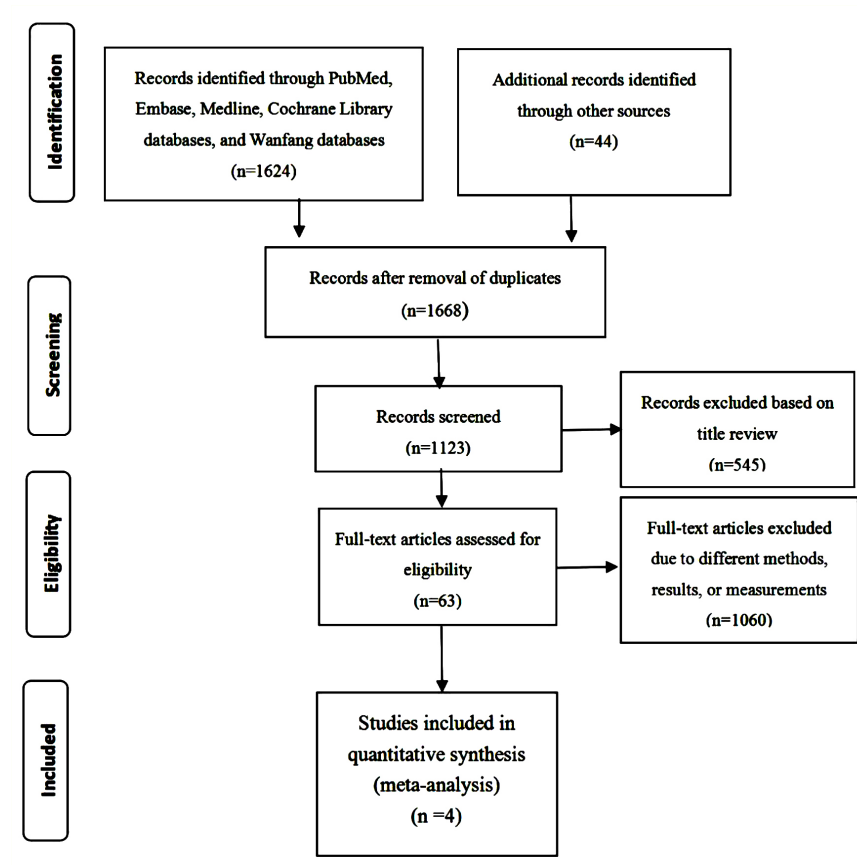

Figure 1: Flow diagram showing the procedure of selecting studies for meta-analysis.

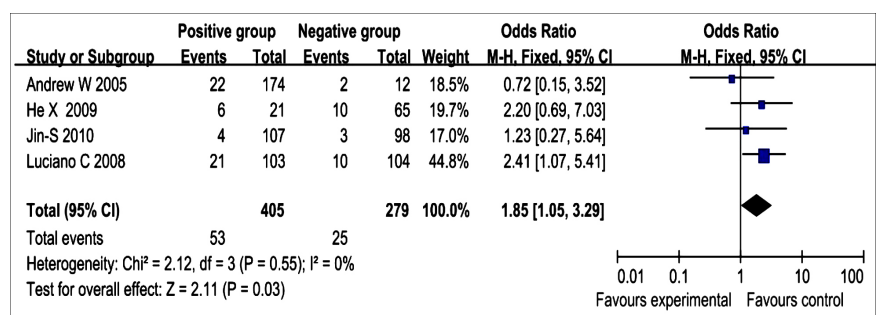

Figure 2: Fixed-effect meta-analysis for major cardiovascular adverse events. The figure shows the number of events, number of patients in the positive and negative groups, odds ratio (OR), and $95 \%$ confidence interval $(\mathrm{Cl})$ for each trial, overall OR estimate with $95 \% \mathrm{Cl}$ and $\mathrm{P}$-value for association test, $\mathrm{p}$ - value for heterogeneity test, and (12) measures of trialinconsistenc.

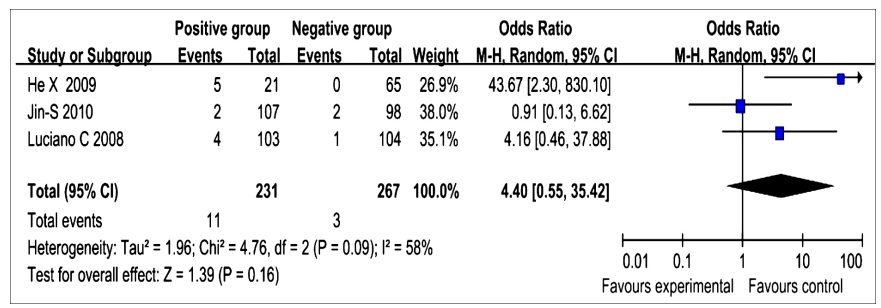

Figure 3: Fixed-effect meta-analysis for cardiac events.

Three investigators independently screened these studies and independently extracted the following data from each study: research design, inclusion and exclusion criteria, research results, the time of publication, duration of follow-up, lead author, sample information, and clinical baseline characteristics. The results of the assessment were short-term endpoints, including the incidence of cardiac death and major cardiovascular adverse events (MACE).

Only three of these studies included cardiac death, ${ }^{10-12}$ and four studies showed the occurrence of MACE. ${ }^{10-13}$

For each type of research bias, Cochrane's risk assessment tool was used to assess each risk of bias. ${ }^{14}$ The processing of the data was based upon statements from the Cochrane Collaboration and PRISMA statements. ${ }^{9}$ Review Manager 5.3 (RevMan) was applied to this meta-analysis. Heterogeneity between researches was analysed applying Chi-square tests of differences and $I^{2}$ statistics of heterogeneity. The low, medium, and high heterogeneity were defined respectively by $25 \%, 50 \%$, and $75 \%$ of the $I^{2}$ value. ${ }^{15}$ The Mantel-Haenszel test would provide summary estimates of their $95 \%$ confidence intervals (Cls) and odd risks (ORs). When $p$ was $<0.05$, the results were identified as different, and the statistical result value were two-tailed.

\section{RESULTS}

A total of 1,668 studies were retrieved initially. After review, 545 with repetitive contents were excluded. Of the 1,123 entries selected, 1,060 literatures that did not match the research, were further removed. Sixty-three selected articles were reviewed in the full text review. Among them, 59 articles (including meta-analysis, reviews, letters to editors, or clinical outcomes without prognosis) were deleted. In the end, four studies were consisted for this meta-analysis (Figure 1). ${ }^{10-13}$

A total of four controlled studies were included in this meta-analysis. The 684 patients with ACS were eventually included in this study (including 405 IMA-positive patients and 279 IMA-negative patients). The average age of the included study population was greater than 60 years. Table I shows the baseline characteristics of the included research. Table II shows the demographic characteristics of the the included research. From the quality evaluation results, every research had a low risk of bias, the NOS scores for these studies were 7 to 8 points by performing methodological quality assessment. ${ }^{16}$

All researchs evaluated the MACE between the IMA-positive group and the IMA-negative group. The results of the MACE were combined and the fixed effect models were compared. There was a significant difference in MACE between the IMA-positive group and the IMA-negative group (OR: 1.85; 95\% Cl: 1.05-3.29; $\mathrm{p}=$ $0.03)$ and low heterogeneity $\left(I^{2}=0 \%\right.$, Figure 2$)$.

Three of all researches evaluated cardiac death between the IMA-positive and IMA-negative groups. Data from three control researches were pooled by random effects models, and no significant differences in cardiac death were found between theIMA-positive and IMA-negative groups (OR: $4.40 ; 95 \% \mathrm{Cl}: 0.55-35.42 ; \mathrm{p}=$ $0.16)$, with moderate heterogeneity among the studies $\left(I^{2}=58 \%\right.$, Figure 3).

\section{DISCUSSION}

IMA is a metabolic variant of albumin. Under specific conditions of hypoxia, acidosis and free radical production in the body, the conformational change of the N-terminus of albumin, and the resulting IMA molecules have weaker binding ability to transition metals (such as cobalt, nickel and copper) than albumin. ${ }^{17}$ Due to the difference in binding ability between IMA and albumin, the concentration of IMA can be measured indirectly by the albumin cobalt binding assay (ACB assay). ${ }^{18}$ 
Table I: Patient characteristics in each study.

\begin{tabular}{|c|c|c|c|c|}
\hline $\begin{array}{l}\text { Demographics } \\
\text { Number of Patients }\end{array}$ & $\begin{array}{c}\text { Worster A } \\
\text { (189) }\end{array}$ & $\begin{array}{c}\text { Consuegra-sanchez L } \\
(207)\end{array}$ & $\begin{array}{c}\text { He XF } \\
(86)\end{array}$ & $\begin{array}{c}\text { Kim JS } \\
(205)\end{array}$ \\
\hline Age, mean \pm S.D & $61.5 \pm 14.5$ & $61 \pm 13$ & $61.38 \pm 11 / 67.23 \pm 10.46$ & $63.7 \pm 11.6$ \\
\hline Male gender (n) & 112 & 142 & 57 & 151 \\
\hline Smoking history $(\mathrm{n})$ & 123 & 49 & NA & 42 \\
\hline Prior CAD $(n)$ & 56 & 46 & NA & NA \\
\hline Hypertension (n) & NA & 92 & NA & 112 \\
\hline Diabetes mellitus (n) & 41 & 30 & NA & 46 \\
\hline Hyperlipidemia (n) & NA & 73 & NA & 107 \\
\hline
\end{tabular}

Table II. Baseline characteristics.

\begin{tabular}{|c|c|c|c|c|c|c|c|c|c|c|}
\hline Author & Year & $\begin{array}{l}\text { Study } \\
\text { methodology }\end{array}$ & Region & $\begin{array}{l}\text { Sample } \\
\text { size } \\
\text { (\% male) }\end{array}$ & $\begin{array}{l}\text { IMA } \\
\text { cutoff }\end{array}$ & Inclusion criteria & Exclusion criteria & Endpoints & Follow-up & $\begin{array}{l}\text { NOS } \\
\text { score }\end{array}$ \\
\hline Worster A & 2005 & Prospective & $\begin{array}{l}\text { United } \\
\text { States }\end{array}$ & $189(59.3)$ & $\begin{array}{l}80 \\
\mathrm{U} / \mathrm{mL}\end{array}$ & $\begin{array}{l}\text { All patient aged } 18 \\
\text { years or older with } \\
\text { potential cardiac } \\
\text { ischemia symptoms } \\
\text { that occurred within } \\
6 \text { hours before their } \\
\text { arrival at the } \\
\text { emergency } \\
\text { department, in whom } \\
\text { the emergency } \\
\text { physician elected to } \\
\text { order a test for } \\
\text { serum concentration } \\
\text { of cardiac troponin I } \\
\text { (cTnl). Participating } \\
\text { patients were } \\
\text { required to provide } \\
\text { reliable contact } \\
\text { information. }\end{array}$ & $\begin{array}{l}\text { Patients referred directly to } \\
\text { trauma or surgery; patients in } \\
\text { whom clinicians documented any } \\
\text { of the study outcomes (death, MI, } \\
\text { congestive heart failure, serious } \\
\text { arrhythmia or refractory ischemic } \\
\text { cardiac pain) before the results of } \\
\text { their first cTnl becoming } \\
\text { available; and patients who } \\
\text { refused study participation. }\end{array}$ & $\begin{array}{l}\text { Serious } \\
\text { cardiac }\end{array}$ & 72 hours & 7 \\
\hline He XF & 2009 & Retrospective & China & $86(66.3)$ & $\begin{array}{l}0.669 \\
\text { ABSU }\end{array}$ & $\begin{array}{l}\text { NSTEMIDSTEMI or } \\
\text { UAP patients with } \\
\text { chest pain within } 12 \\
\text { hours, And } \\
\text { undergoing primary } \\
\text { PCl. }\end{array}$ & $\begin{array}{l}\text { Various infections, acute and } \\
\text { chronic inflammation, trauma, } \\
\text { malignant tumors, connective } \\
\text { tissue diseases, autoimmune } \\
\text { diseases, severe peripheral } \\
\text { vascular disease or peripheral } \\
\text { vascular thrombotic diseases, } \\
\text { stroke, surgery, severe liver and } \\
\text { kidney dysfunction, taking statins } \\
\text { one week before admission } \\
\text { Taking antibiotics or non-steroidal } \\
\text { anti-inflammatory drugs two } \\
\text { weeks before admission. }\end{array}$ & $\begin{array}{l}\text { Death, } \\
\text { MACE. }\end{array}$ & $\begin{array}{l}\text { During } \\
\text { hospitalization. }\end{array}$ & 6 \\
\hline
\end{tabular}

Since serum IMA levels have been used as prognostic indicators for ACS, there has been controversy. Whether level of IMA affects the prognosis of ACS patients has been the focus of controversy. ${ }^{19}$ In patients with ACS, elevated IMA levels increased the incidence of MACE in the short term, but did not increase the incidence of cardiac death. Prognostic features of biochemical markers of cardiovascular disease caused by atherosclerosis have been identified in previous research. Although serum IMA appears to contribute to the clinical diagnosis and evaluation of patients with ACS, it is unclear whether serum IMA levels are associated with prognosis in patients with ACS and promote the treatment of their condition.

This meta-analysis evaluated four cohort studies to systematically assess the short-term impacts of IMA levels on cardiac death and MACE in initially diagnosed ACS patients. It was found that the IMA positivity groups may lead to an increase 
in the incidence of MACE in patients with ACS in the short term (OR: 1.85; $95 \% \mathrm{Cl}$ : 1.05-3.29). There was no statistically significant difference in the incidence of cardiac death between the IMA elevated group and the IMA normal group (OR: $4.40 ; 95 \% \mathrm{Cl}: 0.55-35.42$ ). This study was the first meta-analysis of short-term prognosis for IMA levels in ACS patients. According to this study, serum IMA levels contribute to the prediction of short-term prognosis in ACS patients. Kim and colleagues studied the association between IMA levels and the short-term incidence of cardiac death and MACE in patients with ACS, as this study included many patients with unstable angina due to coronary artery spasm, this group of patients usually has no unstable plaque, so the incidence of cardiac death and MACE was lower than the other three studies included in this meta-analysis. ${ }^{12}$ Angina caused by coronary artery spasm is defined as variant angina pectoris, which belongs to acute coronary syndrome, therefore, these will not affect this research results. ${ }^{20}$ All patients with chest pain were patients with ACS, and the onset time of chest pain was within 12 hours, the IMA was monitored immediately after admission. Worster and colleagues showed that the ACS patients after admission were repeatedly monitored for IMA, and the highest IMA values were included in pooled analysis, which helps the IMA to more accurately display the myocardial ischemia. ${ }^{13}$ On the other hand, the heterogeneity of cardiac mortality between the studies included. From the sensitivity analysis, it was found that the study of He Xuanfang increased heterogeneity. This study was significantly different from the other three studies because all patients enrolled in the study were patients with chest pain within 12 hours. ${ }^{11}$ In some patients with unstable angina in this study, the time from chest pain to monitoring IMA was nearly 12 hours, In this case, only the IMA would undergo a transient increase and then return to normal levels quickly, so the authors consider the IMA measurement of patients with partially unstable angina as false negative. After the study was removed, the heterogeneity of pooled analysis was reduced to low heterogeneity $\left(\mathrm{I}^{2}=0 \%\right)$, and there was no significant difference in the incidence of cardiac death between IMA-positive ACS patients and IMA-negative ACS patients, but because there were only two studies included in our analysis, the introduction of studies was less and the incidence of cardiac death was low, the statistical results showed no statistical difference. Therefore, there has been no change in the research results.

This meta-analysis showed that the incidence of cardiovascular events was significantly higher in the IMA-positive group than in the IMA-negative group during short-term follow-up of ACS patients. Despite the low heterogeneity, there was a statistically significant difference in the incidence of cardiovascular events in IMA-positive patients with ACS. But the incidence of cardiac death was not significantly different between the IMA-positive group and the IMA-negative group. Elevated serum IMA levels may increase short-term risk in patients with acute myocardial ischemia, but poor evidence for cardiomyocyte necrosis (Troponin I-negative).$^{19}$ In terms of prognosis, MACE risk was higher in IMA-positive patients initially diagnosed with ACS, therefore, it was proposed to use it as a prognostic indicator of ACS patients, especially in patients initially diagnosed with acute myocardial infarction. Overall, this meta-analysis showed that IMA levels did provide some prognostic information for the incidence of MACE in patients with ACS, but the rate of cardiac death has no statistically significant difference, since the meta-analysis had only three studies included on the association between IMA levels and cardiac death in patients with ACS. If the authors removed one study that affects heterogeneity by He Xuanfang and colleagues, then only two studies were included in this meta-analysis. Therefore, IMA levels rarely provided information about cardiac death in patients with ACS, and had is no significant guiding value for clinical prognosis.

\section{CONCLUSION}

Elevated serum IMA increases short-term poor prognosis in patients with ACS, and that primary performance increases the incidence of MACE. However, there is no significant increase in cardiac death. Monitoring IMA may help to better risk grading and created personalised treatment strategies. It may contribute to achieve the best care and lower healthcare costs, thereby elevating the quality of personal life, reduce the incidence of hospitalisation and medical costs. If IMA can be introduced into main stream risk grading method, such as the Global Registry of Acute Coronary Events (GRACE) and Thrombolysis in Myocardial Infarction (TIMI) risk scores, it could play a big role in the predictability and accuracy of clinical outcomes. However, elevated serum IMA did not significantly increase the incidence of cardiac death in ACS patients.

\section{ETHICAL APPROVAL:}

All analyses were based on previous published studies, thus no ethical approval was required.

\section{PATIENTS' CONSENT:}

Patients' consents were not required.

\section{CONFLICT OF INTEREST:}

The authors declared no conflict of interest.

\section{ACKNOWLEDGMENT:}

We thank LetPub (www.letpub.com) for its linguistic assistance during the preparation of this manuscript.

\section{AUTHORS' CONTRIBUTION:}

HM, HW, SY: Conceptualisation and supervision. JS, JZ: Data curation, formal analysis, investigation and methodology. HW, SY, HM: Project administration. W, JS, SY: Software. HW, SY: Writing original draft. JZ, HM: Writing review and editing. 


\section{REFERENCES}

1. Ramasamy I. Biochemical markers in acute coronary syndrome. Clin Chim Acta 2011; 412(15-16):1279-96. doi: 10.1016/j.cca.2011.04

2. Stähli BE, Wischnewsky MB, Jakob P. Predictive value of the age, creatinine, and ejection fraction (ACEF) score in patients with acute coronary syndromes. Int J Cardiol 2018; 270:7-13. doi: 10.1016/j.ijcard.2018.05.134.

3. Roffi M, Patrono C, Collet JP. 2015 ESC guidelines for the management of acute coronary syndromes in patients presenting without persistent ST-segment elevatio: Task force for the management of acute coronary syndromes in patients presenting without persistent ST segment elevation of the European society of cardiology (ESC). Eur Heart J 2016; 37(3):267-315. doi: 10.1093/eurheartj/ ehv320.

4. Ennezat PV, Maréchaux S, Pincon C. Anaemia to predict outcome in patients with acute coronary syndromes. Arch Cardiovasc Dis 2013; 106(6-7):357-65. doi: 10.1016/ j.acvd.2013.04.004.

5. Wang $\mathrm{HL}$, Pang $\mathrm{XH}$, Yang JJ. The Prognostic value of heart-type fatty acid binding protein in patients with acute coronary syndrome. J Coll Physicians Surg Pak 2018; 28(1):56-60. doi: 10.29271/jcpsp.2018.01.56.

6. Wu AH, Morris DL, Fletcher DR. Analysis of the albumin cobalt binding (ACB) test as an adjunct to cardiac troponin I for the early detection of acute myocardial infarction. Cardiovasc Toxicol 2001; 1(2):147-51. doi: 10.1385/ ct:1:2:147.

7. Demir MT, Baydin A, Amanvermez R. Comparison of pentraxin-3 and ischemia-modified albumin with troponin in early diagnosis of acute coronary syndrome. Bratisl Lek Listy 2018; 119(8):509-12. doi: 10.4149/BLL_2018_093.

8. Turan T, Akyüz AR, Sahin S. Association between the plasma levels of IMA and coronary atherosclerotic plaque burden and ischemic burden in early phase of non-ST-segment-elevation acute coronary syndromes. Eur Rev Med Pharmacol Sci 2017; 21(3):576-83.

9. Liberati A, Altman DG, Tetzlaff J. The PRISMA statement for reporting systematic reviews and meta-analyses of studies that evaluate health care interventions: Explanation and elaboration. J Clin Epidemiol 2009; 62:e1-34. doi: 10.1016/j.jclinepi.2009.06.006.

10. Consuegra-Sanchez L, Bouzas-Mosquera A, Sinha MK. Ischemia-modified albumin predicts short-term outcome and 1-year mortality in patients attending the emergency department for acute ischemic chest pain. Heart Vessels 2008; 23(3):174-80. doi: 10.1007/s00380-007-1031-8.

11. He XF. Predictive role and clinical significance of serum ischemia modified albumin and deoxyribonuclease I in early diagnosis of acute coronary syndrome. China: The Second Military Medical University.2009; 1-65.

12. Kim JS, Hwang HJ, Ko YG. Ischemia-modified albumin: is it a reliable diagnostic and prognostic marker for myocardial ischemia in real clinical practice. Cardiology 2010; 116(2):123-9. doi: 10.1159/000317091.

13. Worster A, Devereaux PJ, Heels-Ansdell D. Capability of ischemia-modified albumin to predict serious cardiac outcomes in the short term among patients with potential acute coronary syndrome. CMAJ 2005; 172(13):1685-90. doi: 10.1503/cmaj.045194.

14. Julian PTH, Douglas GA, Peter CG. The cochrane collaboration's tool for assessing risk of bias in randomised trials. BMJ 2011; 343:d5928. doi: 10.1136/bmj.d5928.

15. Higgins JP, Thompson SG, Deeks JJ. Measuring inconsis-tency in meta-analyses. BMJ 2003; 327(7414):557-60. doi: 10.1136/bmj.327.7414.557

16. Wells GA, Shea B, O'Connell D. The Newcastle-Ottawa Scale (NOS) for assessing the quality of nonrandomized studies in meta-analysis. 2011; Available: www.ohri.ca/programs/ clinical_epidemiology/oxford.asp.

17. Cournot M, Burillo E, Saulnier PJ. Circulating concentrations of redox biomarkers Do not improve the prediction of adverse cardiovascular events in patients with Type 2 diabetes mellitus. J Am Heart Assoc 2018; 7(5):e007397. doi: 10.1161/JAHA.117.007397.

18. Coverdale JPC, Katundu KGH, Sobczak AIS. Ischemia-modified albumin: Crosstalk between fatty acid and cobalt binding. Prostaglandins Leukot Essent Fatty Acids 2018; 135:147-57. doi: 10.1016/j.plefa.2018.07.014.

19. Yang F, Ma L, Zhang L. Association between serum lipoprotein-associated phospholipase A2, ischemic modified albumin and acute coronary syndrome: A cross-sectional study. Heart Vessels 2019; 34(10):1608-14. doi: 10.1007/ s00380-019-01403-3.

20. Bentivoglio LG, Holubkov R, Phd SFK. Short and long term outcome of percutaneous transluminal coronary angioplasty in unstable versus stable angina pectoris: A report of the 1985-1986 NHLBI PTCA Registry. Cathet Cardiovasc Diagn 2010; 23(4):227-38. doi: 10.1002/ccd. 1810230402. 